\title{
A Comparison of Two Dust Uplift Schemes within the Same General Circulation Model
}

\author{
Duncan Ackerley, ${ }^{1,2}$ Manoj M. Joshi, ${ }^{3}$ Eleanor J. Highwood, ${ }^{1}$ Claire L. Ryder, ${ }^{1}$ \\ Mark A. J. Harrison, ${ }^{4}$ David N. Walters, ${ }^{4}$ Sean F. Milton, ${ }^{4}$ and Jane Strachan ${ }^{1}$ \\ ${ }^{1}$ Department of Meteorology, University of Reading, Reading RG6 6BB, UK \\ ${ }^{2}$ Monash Weather and Climate, Monash University, VIC, Clayton 3800, Australia \\ ${ }^{3}$ National Centres for Atmospheric Science (Climate), University of Reading, Reading RG6 6BB, UK \\ ${ }^{4}$ Met Office, Exeter EX1 3PB, UK \\ Correspondence should be addressed to Duncan Ackerley, duncan.ackerley@monash.edu
}

Received 1 December 2011; Revised 12 April 2012; Accepted 9 May 2012

Academic Editor: Ralph A. Kahn

Copyright ( $\odot 2012$ Duncan Ackerley et al. This is an open access article distributed under the Creative Commons Attribution License, which permits unrestricted use, distribution, and reproduction in any medium, provided the original work is properly cited.

\begin{abstract}
Aeolian dust modelling has improved significantly over the last ten years and many institutions now consistently model dust uplift, transport and deposition in general circulation models (GCMs). However, the representation of dust in GCMs is highly variable between modelling communities due to differences in the uplift schemes employed and the representation of the global circulation that subsequently leads to dust deflation. In this study two different uplift schemes are incorporated in the same GCM. This approach enables a clearer comparison of the dust uplift schemes themselves, without the added complexity of several different transport and deposition models. The global annual mean dust aerosol optical depths (at $550 \mathrm{~nm}$ ) using two different dust uplift schemes were found to be 0.014 and 0.023 - both lying within the estimates from the AeroCom project. However, the models also have appreciably different representations of the dust size distribution adjacent to the West African coast and very different deposition at various sites throughout the globe. The different dust uplift schemes were also capable of influencing the modelled circulation, surface air temperature, and precipitation despite the use of prescribed sea surface temperatures. This has important implications for the use of dust models in AMIP-style (Atmospheric Modelling Intercomparison Project) simulations and Earthsystem modelling.
\end{abstract}

\section{Introduction}

Airborne mineral dust is important in all aspects of Earthsystem modelling as it impacts on the Earth's radiation budget [1]; weather [2], and climate [3,4] while also providing a source of nutrients to oceanic and land biota $[5,6]$.

Despite advances in dust modelling and the representation of dust uplift on a case by case basis (e.g., [79]), such studies have focussed on running a single dust scheme in a given general circulation model (GCM), regional climate model (RCM) or numerical weather prediction (NWP) model. However, the representations of dust uplift, transport and deposition in atmospheric models are still highly uncertain. While some of the uncertainty arises from the parameterization schemes used for representing the dust cycle there are also influences from the driving model, which may also add to the uncertainty.

Modelling intercomparison studies such as the Atmospheric Model Intercomparison Project (AMIP [10]) are important as they aid in understanding model uncertainty and variability across a range of state-of-the art climate models. Similar model intercomparison studies, with a particular focus on mineral dust, can be found in [11] (for the Bodélé Depression in Chad) and [12] (for Asia under the framework of the Dust Model Intercomparison Project, DMIP). The studies by $[11,12]$ identified that dust simulations are particularly sensitive to:

(1) The dust-uplift parameterization scheme.

(2) The representation of surface soil characteristics, which vary between models and will impact on uplift. 
(3) Surface wind speeds: these are typically small-scale processes that are not resolved explicitly given the size of model grid-boxes and therefore need to be parameterized.

Global model studies of aerosol processes [13] highlight the diversity in model output when research groups run their models in "standard" configurations. However, the schemes used by [13] not only contain differences from the parameterization of the dust cycle but also in the capabilities of those overriding atmospheric models to represent the processes that lead to dust uplift, transport and deposition. If the numerous dust schemes employed by the modelling community could be included in an ensemble of simulations that are driven by one GCM, for example, then differences in dust emission, transport, and deposition across the parameterization schemes could be understood better. Differences in modelled dust climatology would in this case be almost entirely governed by the dust cycle parameterization rather than the other parameterized processes in the driving GCMs. Such studies have been undertaken for either specific case studies $[14,15]$ or seasonal dust properties [16]; however, none of these studies [14-16] has looked at the effects of perturbing the uplift parameterization characteristics in multiple-year AMIP-type climatological simulations. Running a single driving GCM for a time period that is long enough to acquire long-term climatological averages is therefore key to this study as it allows us to identify robust differences in the climatological dust distribution that are not influenced by model-generated variability. The work presented in this paper therefore, attempts to make a first step towards understanding the climatological impact of two different dust uplift schemes in one GCM.

Descriptions of the models used are provided in Section 2 and an analysis of the modelled Aerosol Optical Depths (AODs), dust size distributions, deposition, and the impacts of the different dust schemes on the modelled climate are discussed in Sections 3-6. The discussions and conclusions are given in Section 7.

\section{Model Setup and Experiments}

2.1. GCM Description. The HadGEM2-A (Hadley Centre Global Environmental Model version 2-Atmosphere-only) model is a state-of-the-art global general circulation model based on the HadGEM1 model $[17,18]$. Some additional physics changes have been made to the model: these are described in $[19,20]$. The model has 38 layers in the vertical reaching a height of approximately $40 \mathrm{~km}$. The horizontal resolution in the present work is $3.75^{\circ}$ longitude $\times 2.5^{\circ}$ latitude (referred to as $\mathrm{N} 48$ as this is the maximum number of waves that can be represented in the zonal direction).

In addition to the above, a parameterization of land/sea breezes has been implemented in this version of HadGEM2$\mathrm{A}$ in order to alleviate problems in the model associated with underestimation of wind speeds at coastal points (those points that are partially ocean and partially land). A scalar
TABle 1: Particle size ranges for each size bin taken from HadGEM2-A during this study. Further discussion and the derivation of these values are given in [20].

\begin{tabular}{lc}
\hline Dust size bin & Particle radius range $(\mu \mathrm{m})$ \\
\hline 1 & $0.0316-0.1$ \\
2 & $0.1-0.316$ \\
3 & $0.316-1.0$ \\
4 & $1.0-3.16$ \\
5 & $3.16-10.0$ \\
6 & $10.0-31.6$ \\
7 & $31.6-100.0$ \\
8 & $100.0-316.0$ \\
9 & $316.0-1000.0$ \\
\hline
\end{tabular}

term proportional to the cube root of the temperature difference between the land and the ocean fractions of the grid box is added to the calculation of the heat and moisture fluxes. Therefore, when the land-ocean temperature difference is $20 \mathrm{~K}$, the effective wind used to calculate the scalar fluxes is doubled. The addition of the parameterisation results in a significant decrease in the dry rainfall bias that HadGEM1 exhibited over the Maritime Continent region [18].

2.2. Dust Uplift Scheme 1: CLIM. The climatological dust uplift scheme used ordinarily in HadGEM2-A (denoted CLIM from now on) is based on the work by [21]. The version used in this study uses a 9-bin scheme (see Table 1, which contains the size ranges of each bin), where bins 79 represent larger particles than the original 6-bin scheme. Bins 7-9 are used in calculating the total horizontal flux from which the vertical dust flux is calculated (in a similar method to the original work by [21]). The version of CLIM used in this study is similar to the version of the Met Office dust scheme used by UK-HiGEM $[22,23]$ and the HadGEM2 model developers [20]. We have stated where the scheme in this study differs from [20].

To initiate dust uplift, a threshold wind velocity must be reached to overcome the cohesive forces between the dust particles and is known as the threshold friction velocity $\left(U_{t \text { (bins 1-9) }}^{*}, \mathrm{~m} \mathrm{~s}^{-1}\right)$. The threshold friction velocity is calculated for each size bin (see Table 1 for particle sizes) and is very similar to the original setup in [21], given as:

$$
U_{t(\text { bins 1-9) }}^{*}=A\left(r_{p_{(\text {bins 1-9) }}}\right)+B W+C,
$$

where $A\left(r_{p(\text { bins 1-9) }}\right)$ is the dry threshold friction velocity $\left(\mathrm{m} \mathrm{s}^{-1}\right)$ as a function of particle size (for each of the 9 size bins given in Table 1) and is calculated from the derivation given in [24], $W$ is the soil moisture content of the top $10 \mathrm{~cm}$ of the soil $\left(\mathrm{kg} \mathrm{m}^{-2}\right)$, and $B$ and $C$ are constants. $B$ and $C$ were originally derived empirically by [21] in HadCM3, however the values resulted in unrealistic dust uplift when applied to HadGEM2-A. The values were set to 0.10 and -0.08 in this study (following several iterative test experiments) to give the best representation of the aerosol optical depths over Africa.

Once the values of $U_{t(\text { bins 1-9) }}^{*}$ have been calculated, the horizontal flux of dust in each bin can be initiated once the 


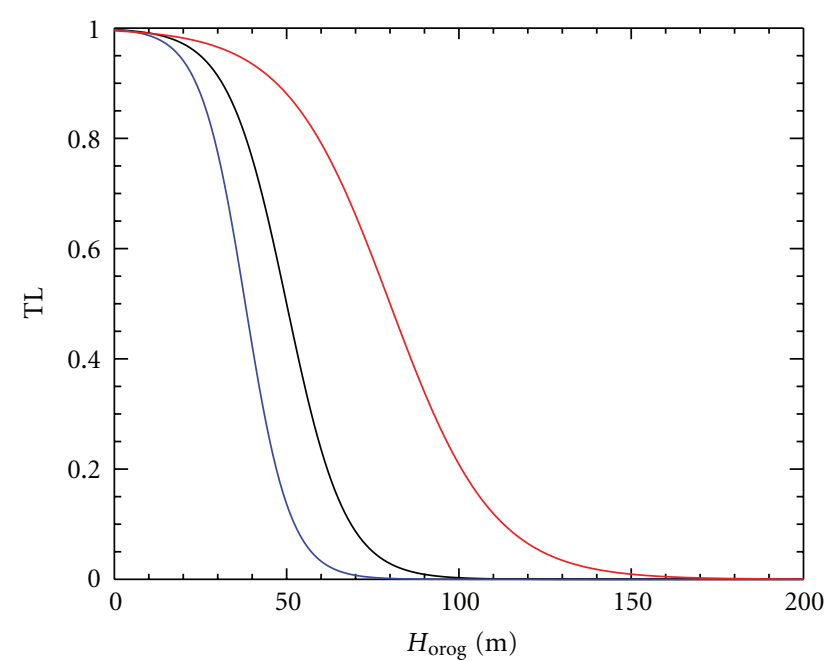

_ Ackerley et al. [27]

- CLIM (see Section 2.2)

- DEAD (see Section 2.3)

FIGURE 1: A plot of the topographic "low" source term as given in (3) (red line), (5) (blue line) and the version used in [27] (black line).

friction velocity over bare soil at the surface $\left(U^{*}, \mathrm{~m} \mathrm{~s}^{-1}\right)$ exceeds $U_{t}^{*}$. The horizontal flux (H(bins 1-9), $\mathrm{kg} \mathrm{m}^{-2} \mathrm{~s}^{-1}$ ) in each bin is calculated from the following:

$$
\begin{aligned}
H(\text { bins 1-9) }= & F_{\text {soil }} C \rho_{*} U^{*^{3}}\left(1+\left(\frac{U_{t(\text { bins } 1-9)}^{*}}{U^{*}}\right)\right), \\
& \times\left(1-\left(\frac{U_{t(\text { bins } 1-9)}^{*}}{U^{*}}\right)^{2}\right) \frac{M_{\text {rel }}}{G} D \mathrm{TL},
\end{aligned}
$$

where $F_{\text {soil }}$ is the fraction of bare soil within a grid box, $\mathrm{C}$ is an empirically derived constant of proportionality (defined in [25]), $\rho_{*}$ is the surface air density over land $\left(\mathrm{kg} \mathrm{m}^{-3}\right)$. $M_{\text {rel }}$ is the mass of dust in each bin relative to the total mass of dust at each grid point and is calculated from the silt, sand and clay fraction values taken from the International Geosphere-Biosphere Programme (IGBP) global soil data set [26], $D$ is a globally uniform tuning parameter (set to 18 in these experiments following a series of test simulations) and TL is the "topographic low" source term (based on the work by [27]), which is calculated as:

$$
\mathrm{TL}=0.5\left(1-\tanh \left(\frac{H_{\mathrm{orog}}-80}{30}\right)\right) .
$$

Where $H_{\text {orog }}$ is half of the peak-to-trough height of the model surface elevation. The values in (3) (shown in Figure 1) were chosen following test experiments and are different to those used in [27] as a result of the lower resolution orography used in this study and the different dust uplift scheme (CLIM). The version of the horizontal flux used by [20] does not use the TL function used in this study.
The vertical dust flux ( $G$ (bins 1 to 6 ), $\mathrm{kg} \mathrm{m}^{-2} \mathrm{~s}^{-1}$ ) is then calculated for bins 1 to 6 from:

$$
\begin{aligned}
G(\text { bins } 1 \text { to } 6)= & H(\text { bins } 1 \text { to } 6) *\left(1+\frac{\sum H(\text { bins } 7 \text { to } 9)}{\sum H(\text { bins } 1 \text { to } 6)}\right) \\
& * 10^{\left(13.4 F_{c}-6.0\right)} .
\end{aligned}
$$

As can be seen in (4), modelled dust particles in bins 7-9 are not subject to vertical transport as they are too large; however, the dust in these bins contributes to the saltation and sandblasting that occurs during horizontal dust transport, which is also responsible for liberating smaller particles. $H$ (bins 1 to 6 ) is the horizontal dust mass flux for bins 1 to $6, \Sigma H$ (bins 7 to 9 ) is the total horizontal dust mass flux in bins 7 to $9, \Sigma H$ (bins 1 to 6 ) is the total horizontal dust mass flux in bins 1 to 6 , and $F_{c}$ is the clay fraction of the soil. The middle expression in the brackets increases the horizontal dust flux in each bin to account for the extra saltation and sand blasting from the large dust particles in bins 7 to 9 and is an extension to the relationship derived in [21]. The vertical flux term used is identical to that used in [20].

For more recent developments of the Met Office Unified Model's (MetUM) dust scheme, see [19, 20, 25].

2.3. Dust Uplift Scheme 2: DEAD. The dust uplift scheme from the freely available "mineral dust entrainment and deposition model" (DEAD, [28]) was downloaded and incorporated into the MetUM by [27]. Initial tests using the DEAD scheme from [27] resulted in excessive global emissions of dust in the N48 model (not shown). Therefore several adaptations were made to reduce the dust uplift in the model. The changes to the parameterizations given in [27] are:

(1) The factors in the topographic "low" source term (TL) were changed to the following:

$$
\mathrm{TL}=0.5\left(1-\tanh \left(\frac{H_{\mathrm{orog}}-38}{13}\right)\right) .
$$

As a result of the lower resolution orography used in this study. Equation (5) (shown in Figure 1) is more stringent than the version in [27] (also shown in Figure 1), which is associated with the greater smoothing of surface orography at the N48 resolution used in this study. $H_{\text {orog }}$ is half of the peak-to-trough height of the model surface elevation (m).

(2) Following several iterative test simulations, the global tuning parameter (GT) was increased to 0.016 from 0.014 used in [27].

(3) The gravimetric water content included an extra factor of the surface clay fraction as derived by [29] (see Equation (5) in [28]), which was not included in the [27] version. [28] multiplied the function by a model dependent "ad hoc" coefficient, which was included and set to 0.1 in this study (similar to GT) following the test runs. 
Apart from the changes listed in this section, all other aspects of the dust uplift scheme (such as the horizontal and vertical flux calculations) are identical to those given in [27]. This includes the use of the same globally fixed size distribution for the emitted dust used by [27]. Also, the DEAD uplift scheme only used bins 1-6 for both the vertical and horizontal fluxes (see Table 1 for the size ranges) as in [27].

2.4. Experiments. Two GCM simulations were undertaken with one using the CLIM uplift scheme and the other using DEAD (the transport and deposition schemes are identical for CLIM and DEAD and are discussed in more detail in [21]). Both experiments used AMIP sea-surface temperatures (SSTs) as boundary conditions, and ran for 17 years from 1979-1995. The first year of both model integrations were regarded as spin-up and not included in this analysis.

\section{Aerosol Optical Depth at $550 \mathrm{~nm}$}

The aerosol optical Depth (AOD) is a parameter that is derived in many global and regional atmospheric models including HadGEM2-A (see $[23,27]$ ) and is also retrieved from numerous ground-based and satellite based instruments [30, 31]. The model derivation for calculating the AODs can be found in [32]. The values have also been derived in a selection of atmospheric models as part of the AeroCom project (see $[13,33]$ ). [34] found that the global annual mean AOD values (all reference to AOD will be at 550 $\mathrm{nm}$ ) ranged from $0.01-0.053$ with a median value of 0.023 when simulating the year 2000. The simulated annual mean AODs at $550 \mathrm{~nm}$ over the full 1980-1995 period were 0.014 (CLIM) and 0.023 (DEAD), which both lie within the range given in [34] using AeroCom simulations. However, as the AeroCom simulations were only representative of the year 2000, the range given in [34] may not be representative of the long-term dust induced AOD unlike the 16-year averages for the CLIM and DEAD simulations.

The time series of the annual mean AOD has been plotted for both models in Figure 2 along with the full (dotted lines) and " $80 \%$ of models" (dashed lines) range estimated in [34]. Nine of the sixteen years simulated using the CLIM scheme lie within the [34] range of which two lie within the " $80 \%$ of models" range. All of the modelled annual mean AODs using the DEAD scheme lie within the [34] range and all but three lie within the range of the middle $80 \%$ estimated by the AeroCom models. While the description above is not a comparison between identical simulations, the values from the simulations using CLIM and DEAD lie within the same order of magnitude as the [34] simulations. Also, the majority of the simulated annual mean AOD estimates using CLIM and DEAD lie within the total range of modelled AODs in [34], which gives further confidence in each models' dust simulation.

Reference [23] discussed the global distribution of dust using maps of global AOD associated with dust and biomass aerosol. Similar maps are given in Figure 3 (for dust only)

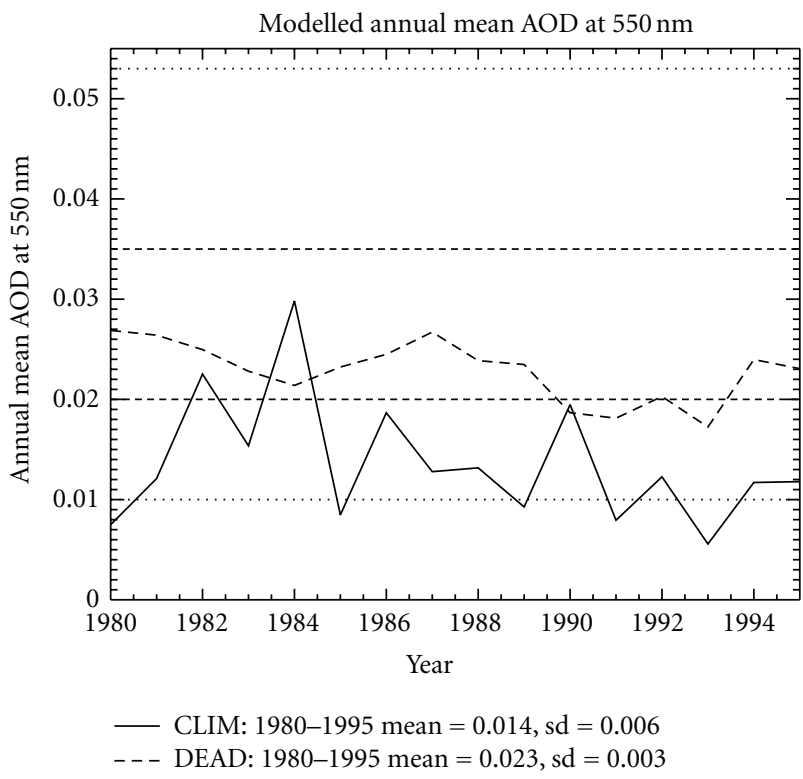

Figure 2: Time series of global, annual mean AOD $(550 \mathrm{~nm})$ for the simulations with the CLIM (solid) and DEAD (dashed) dust uplift schemes. The full and " $80 \%$ of models" ranges estimated by [34] are given by the dotted and dashed lines, respectively.

and show the distribution of dust resulting from using the CLIM and DEAD schemes. Both CLIM and DEAD have peak dust AODs over West Africa in the annual mean (see Figures $3(\mathrm{a})$ and $3(\mathrm{~b})$ ), which is similar to [23]. The values of AOD over West Africa are higher with the CLIM scheme than those of the DEAD scheme. The dust concentrations in the Northern Hemisphere $(\mathrm{NH})$ are also larger than in the Southern Hemisphere ( $\mathrm{SH}$ ) (again similar to [23]) as there is a larger proportion of land in the $\mathrm{NH}$ and therefore more source regions (such as the Sahara Desert). The largest contribution in the SH dust load using both uplift schemes comes from Australia.

Despite the similarities between the two schemes there are some differences (compare Figures 3(a) and 3(b)). The AODs are much lower (less than 0.002) in CLIM north of $60^{\circ} \mathrm{N}$ and south of $30^{\circ} \mathrm{S}$ than in the simulation with DEAD, which may be associated with weaker transport to areas remote from dust sources (for CLIM). Conversely, the CLIM simulation has higher AODs closer to the dust source areas (such as West Africa) and may be associated with a higher vertical mass flux than for DEAD. Despite these differences the main global dust sources (Sahara, Asia, and Australia) that are apparent in both simulations and the global distributions of dust given in Figure 3 are similar to those of other studies $[22,23]$.

\section{Dust Size Distributions}

While there were many similarities between the global dust distributions given in Figure 3, the AODs of the two model simulations differed greatly in regions remote from the main dust sources (e.g., in the polar regions). As the 


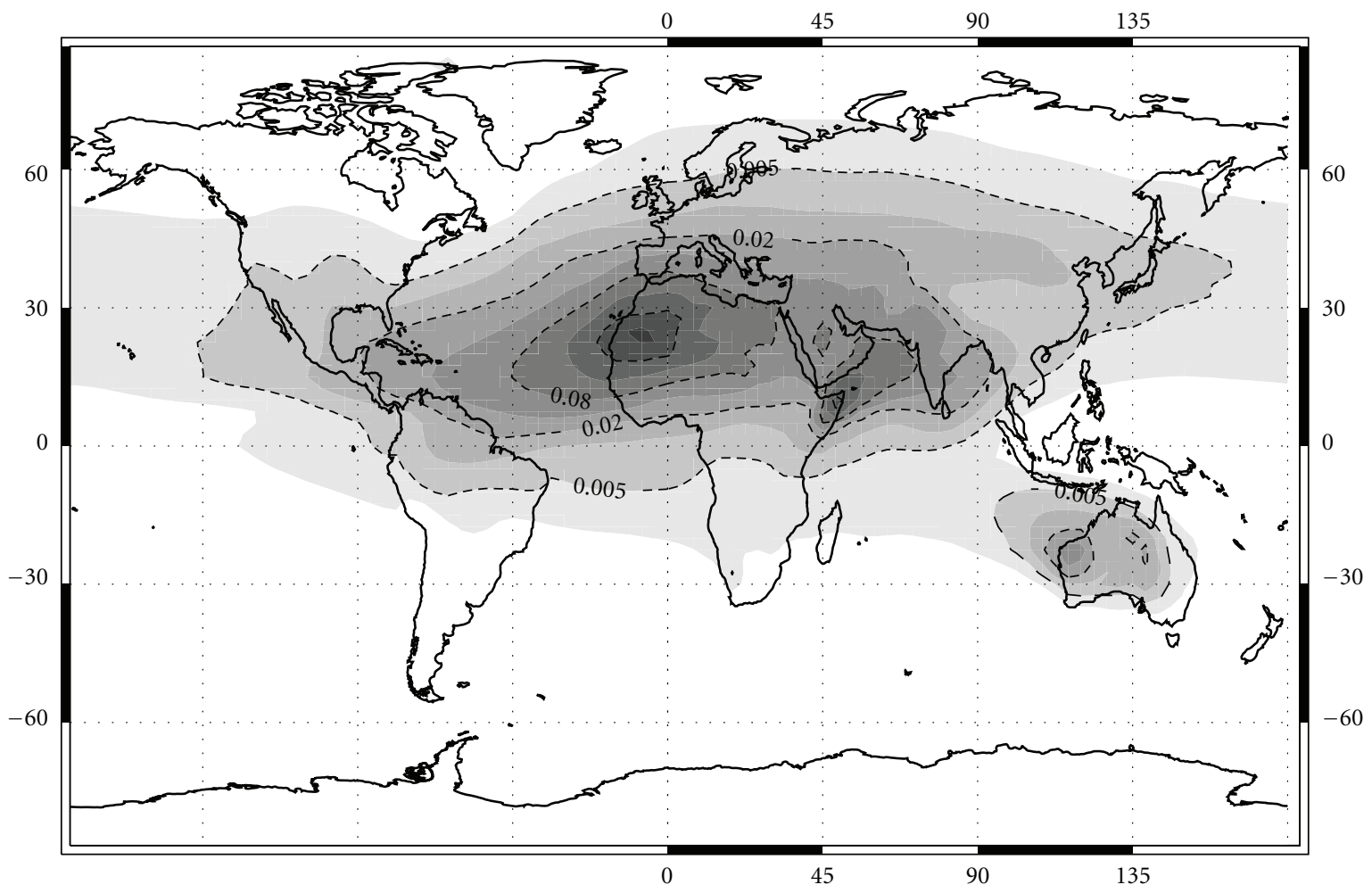

(a)

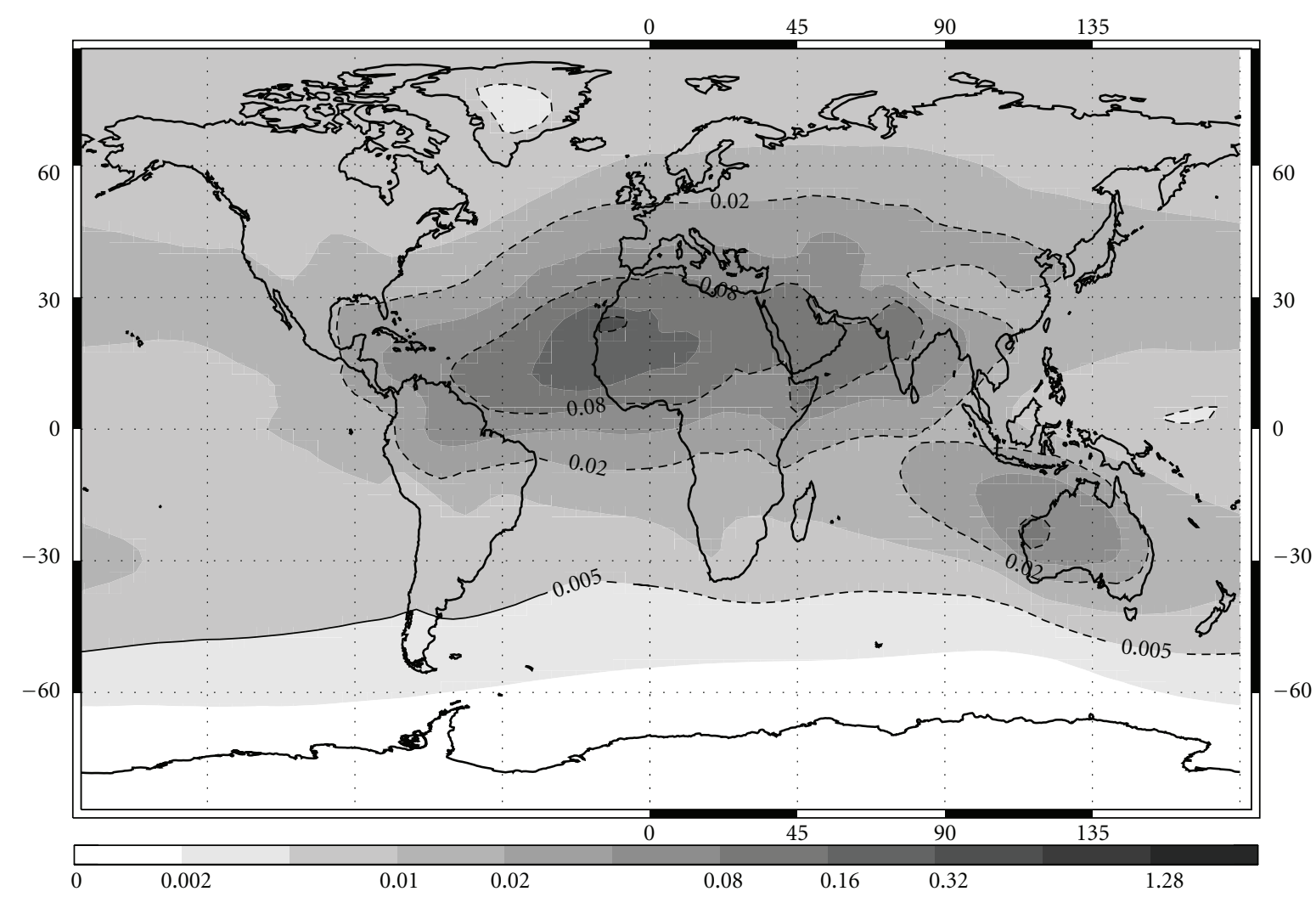

(b)

FigURE 3: Annual mean AOD at $550 \mathrm{~nm}$ for (a) CLIM and (b) DEAD averaged over the last 16 years of each model simulation. 


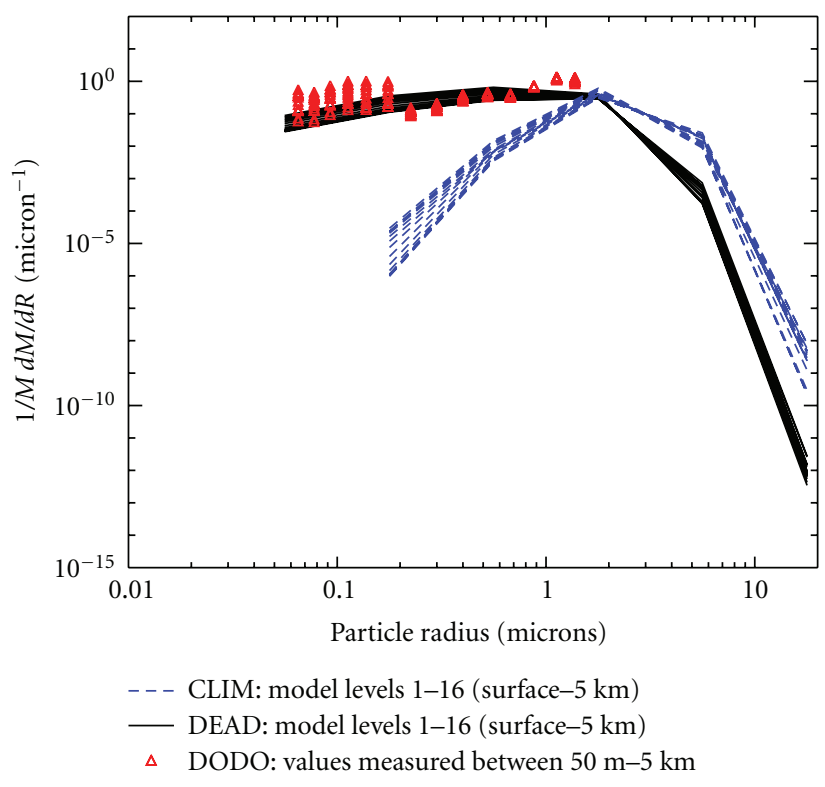

(a)

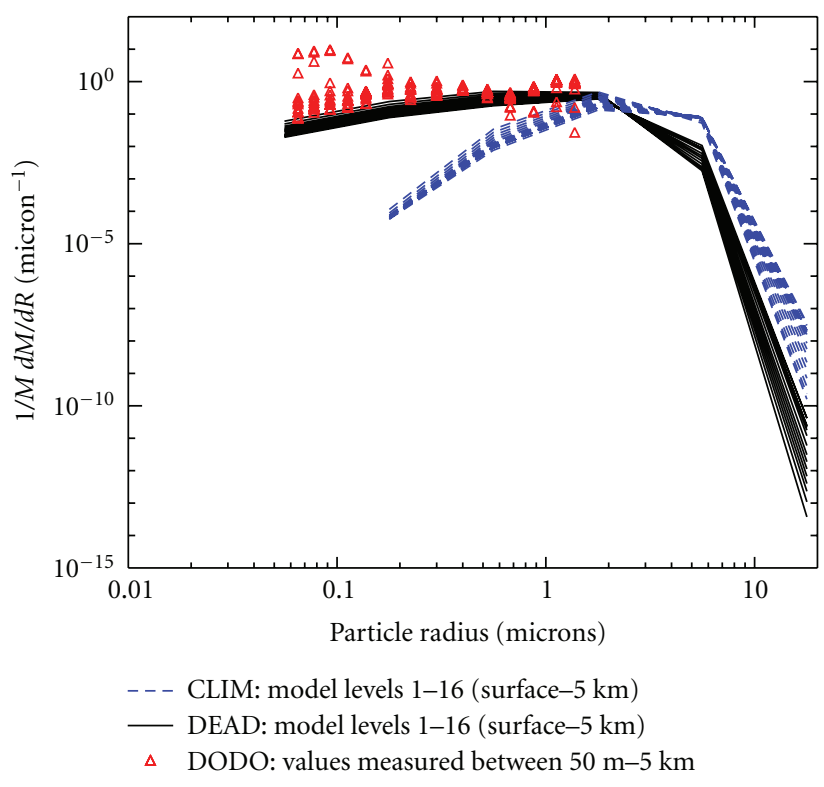

(b)

Figure 4: Normalised mass size distributions as a function of particle radius taken at $330^{\circ} \mathrm{E}$ and $17.5^{\circ} \mathrm{N}$ in CLIM (dashed blue lines) and DEAD (solid line) at each of the levels 1-16 (approximately from the surface to $5 \mathrm{~km}$ ) for (a) DJF and (b) JJA. Corresponding values of the normalised mass size distribution from the DODO campaigns, between the surface and $5 \mathrm{~km}$, (red triangles) are overlaid for (a) DJF and (b) JJA.

simulation using CLIM has lower AODs in remote regions than DEAD and as both schemes use identical dust transport and deposition schemes, it is likely that the size distribution of the dust transported throughout the model domain of the simulation using CLIM is different to the one simulated using DEAD.

To compare the size distributions in each model, we make use of airborne size distribution measurements collected during the Dust Outflow and Deposition to the Ocean experiment (DODO, see [35] for more details on the flight campaigns), which were subsequently used in the case study analysis by [27]. The flight campaign observations were taken during February and August 2006 in the vicinity of the West African coast at various heights above the surface. To compare with the DODO observations the DecemberJanuary-February (DJF) and June-July-August (JJA) seasonal mean, mass weighted dust size distributions at $330^{\circ} \mathrm{E}$ and $17.5^{\circ} \mathrm{N}$ were taken from each model as being representative of dust transported off the African coast. Mass weighting the distributions allows a fairer comparison between the DODO observations (individual specific events) and the model-simulated output (climatological averages), as this will reduce any bias in the dust size distributions caused by individual dust events. The height of the observed data varied between approximately $50 \mathrm{~m}$ and $5 \mathrm{~km}$ and so the model output at levels 1 to 16 (surface to approximately $5 \mathrm{~km}$ above the surface) were taken to compare with the DODO observations.

The DJF dust size distributions for the models and observations are shown in Figure 4(a). The observed size distributions were taken from various heights and positions over West Africa. The observations were included this way to give an idea of the range in possible size distributions taken during the DODO flights. Firstly, the DEAD scheme simulation contained more mass in bins 1,2 and 3 (see Table 1 for size ranges) than in the CLIM scheme simulation. This indicates why the DEAD scheme has higher AODs in regions remote from the major global dust sources than CLIM. The smaller particles in the DEAD simulation can be transported further before deposition occurs (relative to CLIM) and therefore persist in the atmosphere longer to influence the model's radiation field northward (southward) of $60^{\circ} \mathrm{N}\left(30^{\circ} \mathrm{S}\right)$.

In comparison to the DODO observations, the DEAD scheme compares better with the DODO observations than CLIM, which contains very little dust in bin 1 . However, there is no information from observations on the distribution of larger particles, which CLIM may represent better than DEAD. Although the size distribution measurements were taken over only a few days in February 2006, they appear to be representative of the seasonal average as several other more recent aircraft campaigns have measured a similar slope of the accumulation mode size distribution [36, 37].

The size distributions for JJA are given in Figure 4(b) and highlight again the larger proportion of smaller particles in DEAD compared to CLIM although DEAD has a better overall representation of the size distribution than CLIM. Again, the CLIM simulation contains almost no mass in bin 1 , which does not agree well with the observations. Again, the main caveat is that the observed size distributions were taken in August and may not be representative of a seasonal mean; however, the biases appear to be systematic for both schemes over both seasons. 


\section{Deposition}

The global transport and deposition of dust is important not just in terms of the local radiative forcing and the remote circulation anomalies that the presence of atmospheric dust generates, but also in terms of the whole Earth system $[38,39]$. In some regions of the ocean, primary production by phytoplankton is limited by iron: dust that settles onto the sea surface containing iron can therefore fertilise ocean ecosystems and play an important role in regulating the entire carbon cycle. For this reason one important metric of the skill of a dust transport scheme in an Earth system context is the amount of dust transported to the oceans, and especially the southern oceans, where the effect on atmospheric $\mathrm{CO}_{2}$ may be highest [39]. Also, Saharan dust transport and deposition to the Atlantic Ocean is particularly important in providing iron, potassium and other nutrients for ocean biological organisms.

To evaluate the model performance with respect to deposition, this study made use of data from the Dust Indicators and Records in Terrestrial and Marine Paleoenvironments (DIRTMAP) database [40-42]. Twelve stations were used and are given in Table 2 and their locations have also been plotted in Figure 5(a). Both marine sediment trap (with more than one thousand consecutive recorded days) and ice core data were used to provide the best estimate of the climatological mean dust deposition from the observations. The observed and modelled deposition values are plotted for both CLIM and DEAD in Figures 5(b) and 5(c). As the deposition schemes used in the CLIM and DEAD simulations are identical any differences in deposition between the two simulations can only be caused by the use of different uplift schemes. For the CLIM scheme deposition, eight of the twelve model points lie within a factor of ten of the observed deposition and for the DEAD scheme all twelve lie within a factor of ten of the observations. The range of values given in Figures 5(b) and 5(c) lie within the spread of model values given by [34].

The deposition in the DEAD and CLIM schemes are similar at 4 points $(4,5,7$, and 9 , see Figure 5 and Table 2 for the locations), which are all in Greenland except for the marine sediment trap in the Sargasso Sea (9 in Table 2). This suggests that the westward and northward transport of dust over the Atlantic Ocean is similar in the two models. While the transport to the Sargasso Sea and eastern Greenland compare very well with the observations there is higher dust deposition than observed over central Greenland.

Both dust schemes simulate the deposition to Antarctica well (points 1, 3, and 8, see Table 2 and Figure 5 for the locations) with DEAD overestimating and CLIM only slightly underestimating the amount of dust deposited in Antarctica. The difference is likely to be due to CLIM having a smaller proportion of fine particles than DEAD (as discussed in Section 4), which implies that a higher percentage of the dust is deposited before reaching Antarctica.

Both CLIM and DEAD simulate too little dust deposition in north-western Greenland (2 in Table 2 and Figure 5), which may be associated with too much deposition over
TABle 2: Names, data types, and locations of the DIRTMAP deposition data. The numbers on the left hand side of the first column correspond with those in Figure 5.

\begin{tabular}{lccc}
\hline $\begin{array}{l}\text { Site ID (numbers } \\
\text { correspond with Figure 5). }\end{array}$ & Data source & $\begin{array}{c}\text { Longitude } \\
\text { (degrees) }\end{array}$ & $\begin{array}{c}\text { Latitude } \\
\text { (degrees) }\end{array}$ \\
\hline (1) Byrd & Ice core & -120 & -80 \\
(2) Camp century & Ice core & -61 & 77 \\
(3) Dome C & Ice core & 124 & -75 \\
(4) Dye 3 & Ice core & -44 & 65 \\
(5) GRIP summit & Ice core & -38 & 73 \\
(6) Huascarán & Ice core & -78 & -9 \\
(7) Renland & Ice core & -27 & 71 \\
(8) Vostok & Ice core & 107 & -78 \\
(9) Sargasso & Marine sediment & -64 & 32 \\
& trap & & \\
(10) East & Marine sediment & 69 & 15 \\
(11) Cast & trap & & \\
(12) Wast & Marine sediment & 65 & 14 \\
& trap & & \\
\hline
\end{tabular}

the ice sheet as deposition was overestimated in central Greenland.

Finally, the CLIM scheme overestimates the deposition over western South America and the northern Indian Ocean $(6,10,11$, and 12 , see Table 2 and Figure 5 for the locations), which is again likely to be due to the advection of the large particles downwind from the African and Asian dust sources. The deposition in the model using the DEAD scheme compares well with the observations in the northern Indian Ocean but slightly underestimates the deposition in western South America. The modelled deposition into the Atlantic and towards Antarctica compares well with the observations and so both regions are considered in the next sections.

5.1. North Atlantic. The aim of DODO was to quantify the seasonal dust footprint from the Sahara to the Atlantic Ocean and subsequently estimate the iron deposition along with the variability in that flux. The dust deposition into the Atlantic needs to be compared to estimates in other work to identify whether the models are representing the real world well.

For this study, a region of the North Atlantic has been chosen in which to quantify the dust deposition to the surface and is shown in Figures 5(a) and 6. The region is similar in size to that used in the study by [31], which derives North Atlantic dust deposition from satellite data. The annual mean dust deposition and variability into the North Atlantic region can be seen in Table 3. The deposition from CLIM is much higher than for DEAD (almost a factor of 12) and CLIM also displays a much higher variability (more than 10 times) than DEAD. However, the coefficients of variation (standard deviation divided by the mean) are very similar for both simulations (Table 3 ), which imply that the apparent larger variability in CLIM is likely to be due to the larger mean deposition relative to DEAD. 


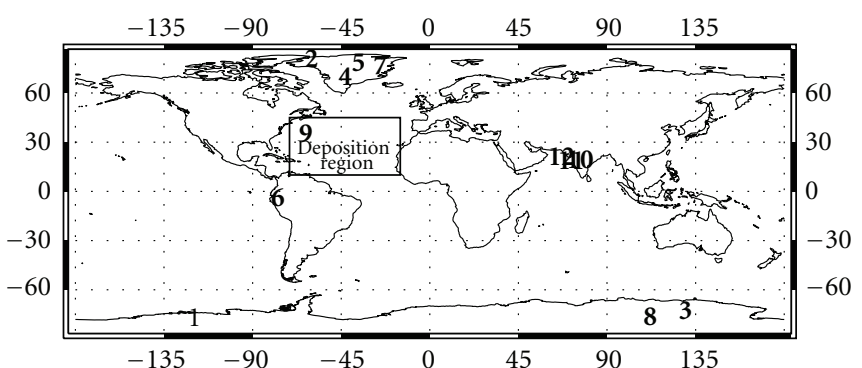

(a)

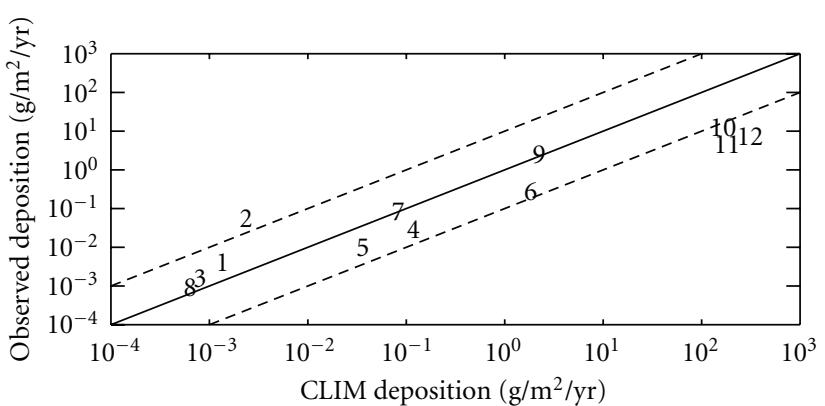

(b)

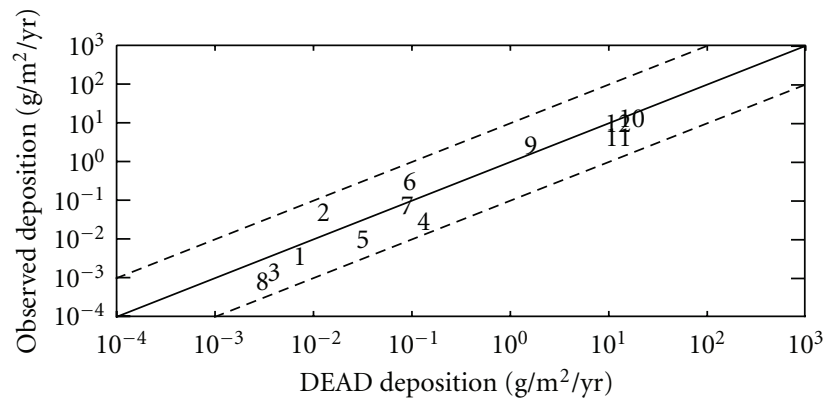

(c)

FIgURE 5: (a) The location of the DIRTMAP stations (1-9, see Table 2) used in this study and scatter plots of the DIRTMAP and nearest model grid box estimated deposition $\left(\mathrm{g} \mathrm{m}^{-2} \mathrm{yr}^{-1}\right.$ ) for (b) CLIM and (c) DEAD uplift schemes. Also shown in (a) is the area under consideration for the dust deposition values given in Table 3 and referred to in Section 5.1. Note in (c) that points 10, 11, and 12 lie close to the same point.

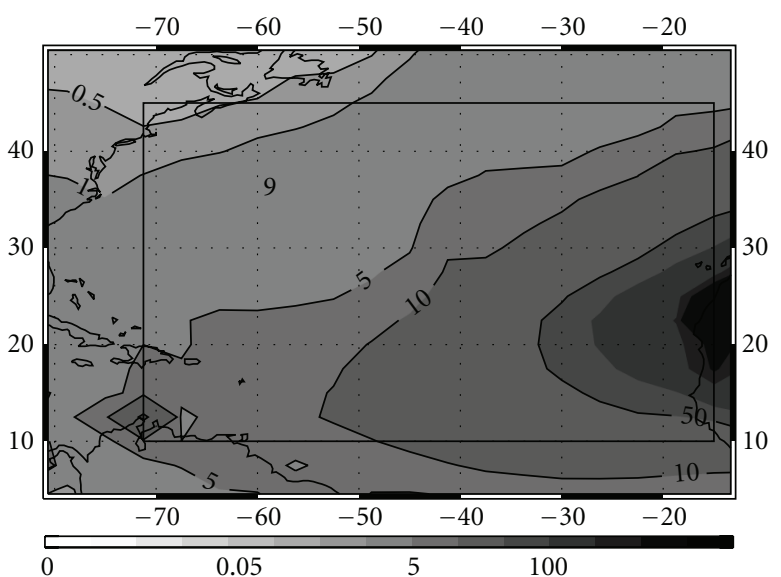

(a)

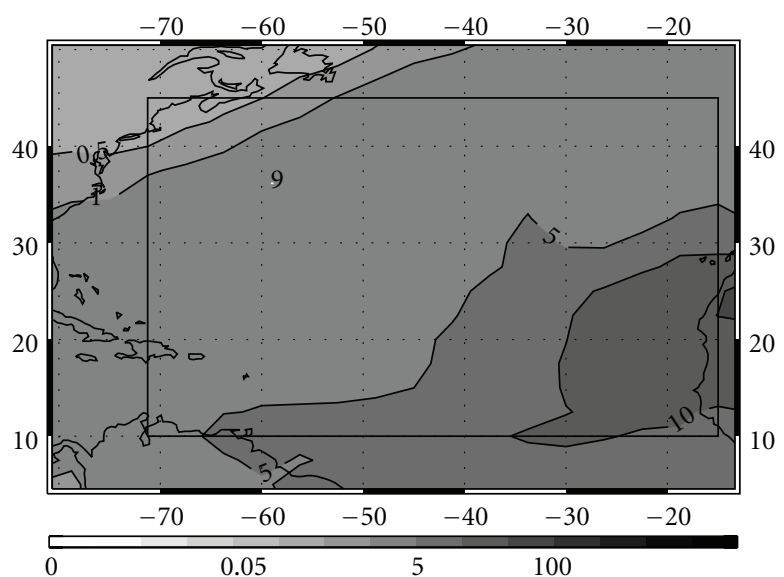

(b)

Figure 6: Deposition into the North Atlantic $\left(\mathrm{g} \mathrm{m}^{-2} \mathrm{yr}^{-1}\right)$ for (a) CLIM and (b) DEAD. The box and the "9" correspond to the box and DIRTMAP observation location given in Figure 5(a).

[31] suggest that the annual deposition from Africa to the Atlantic Ocean (in a similar region to Figure 6) is $140 \pm 40$ $\mathrm{Tg}$ dust, which agrees reasonably well with the value given in Table 3 for DEAD. The deposition into the region in Figure 6 for CLIM lies outside the error bounds for the [31] estimate and also lies outside the estimates for other studies (see Table 3 in [31]). However, in both simulations, the modelled deposition in the Sargasso Sea (point 9, Table 2 and Figure 5) compares very well with the DIRTMAP deposition and suggests that further downstream from the Sahara the deposition is comparable between CLIM and DEAD, which can also be seen in Figure 6.

The higher deposition in CLIM is due to the size distribution of the transported dust (see Section 4) with large deposition rates adjacent to the West African coast, near the Saharan source (Figure 6(a)). By the time the prevailing easterlies have transported the dust to the West Atlantic, the majority of the large particles have been deposited and 
Table 3: Annual (ANN) mean dust deposition into the North Atlantic for the region shown in Figures 5(a) and 6. Also included are the standard deviation, the coefficient of variation and the maximum and minimum deposition amounts of all modelled years.

\begin{tabular}{lcccc}
\hline & $\begin{array}{c}\text { ANN mean, } \\
\mu \text { (Tg dust) }\end{array}$ & $\begin{array}{c}\text { Standard } \\
\text { deviation, } \\
\sigma \text { (Tg dust) }\end{array}$ & $\begin{array}{c}\text { Coefficient of } \\
\text { variation } \sigma / \mu\end{array}$ & $\begin{array}{c}\text { Maximum/ } \\
\text { minimum } \\
\text { (Tg dust) }\end{array}$ \\
\hline CLIM & 1356 & 398 & 0.29 & $1826 / 691$ \\
DEAD & 116 & 35 & 0.30 & $164 / 56$ \\
\hline
\end{tabular}

the deposition rates become comparable with DIRTMAP. Therefore, the high deposition amounts in CLIM cannot be ruled out as erroneous as deposition in other regions of the globe is comparable to DIRTMAP, although the high deposition values in the Indian Ocean (points 10, 11, and 12, Figures 5(b) and 5(c)) suggest there may be too much dust transported in CLIM.

5.2. Southern Ocean and Antarctica. Figure 7 shows that the simulation using the CLIM scheme results in more deposition of dust north of $47^{\circ} \mathrm{S}$ compared to the DEAD scheme. However, at all latitudes south of $47^{\circ} \mathrm{S}$ DEAD has higher deposition relative to CLIM. It is no coincidence that this latitude is the location of the Southern Ocean storm track, and the results of Figure 7 are consistent with the more numerous small particles in DEAD being advected into the southern polar region. In addition, the higher dust AODs exhibited by DEAD compared to CLIM south of $30^{\circ} \mathrm{S}$ in Figure 3 are consistent with observations of dust density in CLIM being too low in this region (see Figure 8 in [21] for King George's Island, Palmer Station, and Mawson station data). This can also be seen in the Antarctic (points 1, 3, and 8 in Figure 5) where CLIM underestimates and DEAD overestimates the dust deposition.

Observations of dust deposition are extremely sparse in the Southern Ocean region however. Although some measurements suggest that the reduction in deposition with latitude is perhaps more consistent with DEAD than CLIM [40], many more observations of dust deposition are needed before any conclusions can be drawn about the relative performance of DEAD and CLIM in depositing dust in the Southern Ocean.

\section{Impacts on the Modelled Climate}

We now discuss the effects of the differing spatial characteristics of the dust on the modelled climate. We confine ourselves to the JJA season, as this is the season with the largest differences between the CLIM and DEAD cases. Figure $8(\mathrm{a})$ shows the temperature difference at $1.5 \mathrm{~m}$ for DEAD relative to CLIM. Overall, the land surface is slightly cooler (particularly in Northern Africa and the Middle East), consistent with the higher dust AOD in DEAD, which intercepts incoming solar radiation over a greater area than CLIM. However, this signal is reversed in western Africa, where DEAD is warmer than CLIM and has lower dust AODs. The air temperatures at $200 \mathrm{hPa}$ do not have the same

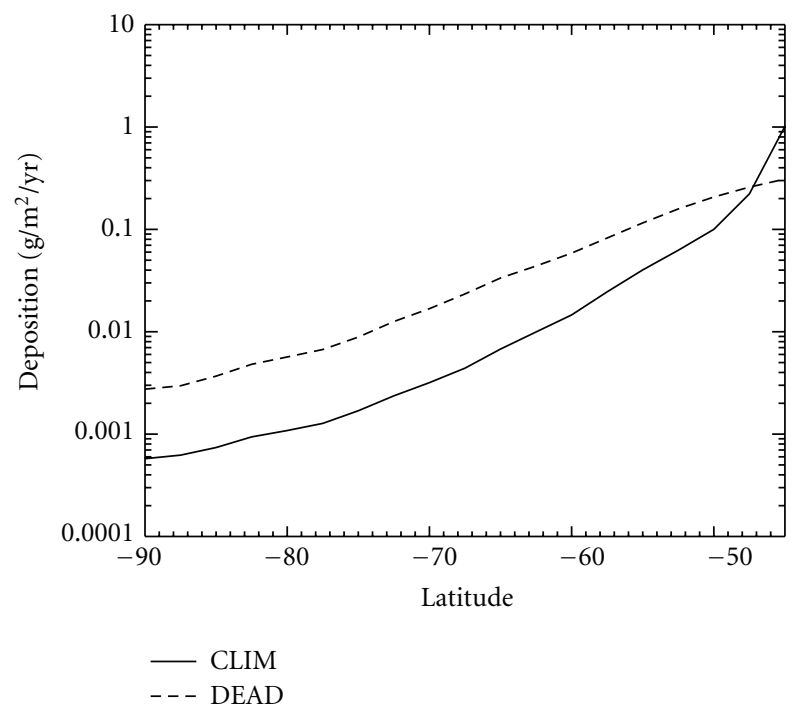

Figure 7: Zonal annual mean dust deposition $\left(\mathrm{g} \mathrm{m}^{-2} \mathrm{yr}^{-1}\right)$ for CLIM (solid line) and DEAD (dashed line) south of $45^{\circ} \mathrm{S}$. Note: the $y$-axis is logarithmic.

dipole structure over western Africa (not shown) as those seen in the surface air temperatures, which indicates that the pattern in Figure 8(a) is a low-level structure.

The pattern evident in Figure 8(a) does have an effect on local circulation in western Africa. Figure $8(\mathrm{~b})$ shows that a high-pressure anomaly exists in JJA in DEAD relative to CLIM; associated with this pressure anomaly is an anticyclonic circulation anomaly, as shown in Figure 9 at $850 \mathrm{hPa}$. The circulation anomaly has an effect on the west African monsoon circulation, as it transports dry air southwestwards toward the monsoonal region, the result is a small decrease in precipitation and relative humidity $(\mathrm{RH})$ at $850 \mathrm{hPa}$ over west Africa, as shown in Figures 10(a) and 10 (b).

While the local effects are considerable, which is unsurprising given the large differences in dust AOD over Africa, some remote effects are evident from Figures 9 and 10. There is some evidence for an effect on the South Asian monsoon, with anomalous easterly winds off the coast of Somalia, and anomalous westerlies over southeastern Asia. Figure 10 also shows a reduction in precipitation over the equatorial Indian Ocean.

\section{Discussion and Conclusions}

The work presented in this study has attempted to identify the differences arising in the representation of dust in a GCM by using two separate uplift schemes. By incorporating two different schemes in one GCM, we have been able to understand how each uplift model responds to the simulated GCM climate and subsequently how the GCM responds to the differences in dust uplift from the two schemes.

Both simulations (CLIM and DEAD) had global annual mean AODs at $550 \mathrm{~nm}$ (averaged from 1980-1995) that lay within the range simulated by the AeroCom project [33]. 


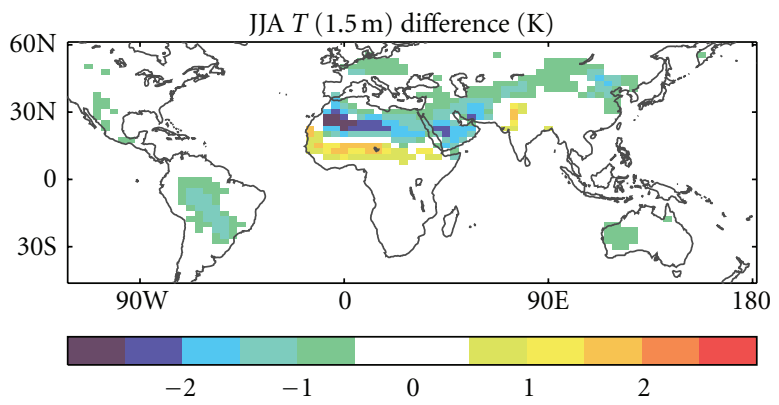

(a)

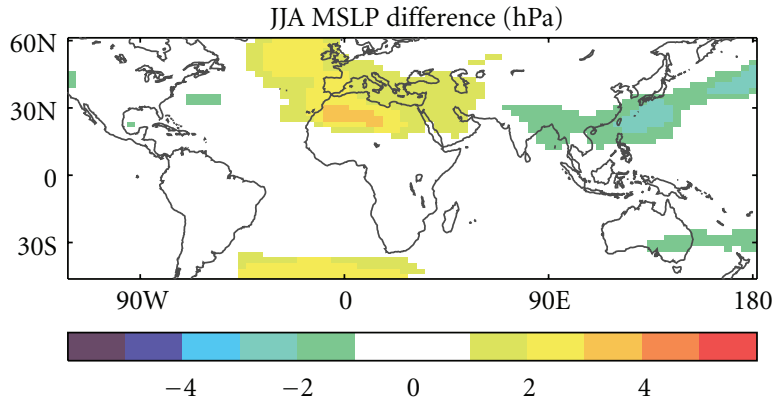

(b)

Figure 8: The difference in JJA (a) surface air temperature at $1.5 \mathrm{~m}(\mathrm{~K})$ and (b) mean sea level pressure (MSLP, hPa)) for DEAD relative to CLIM.

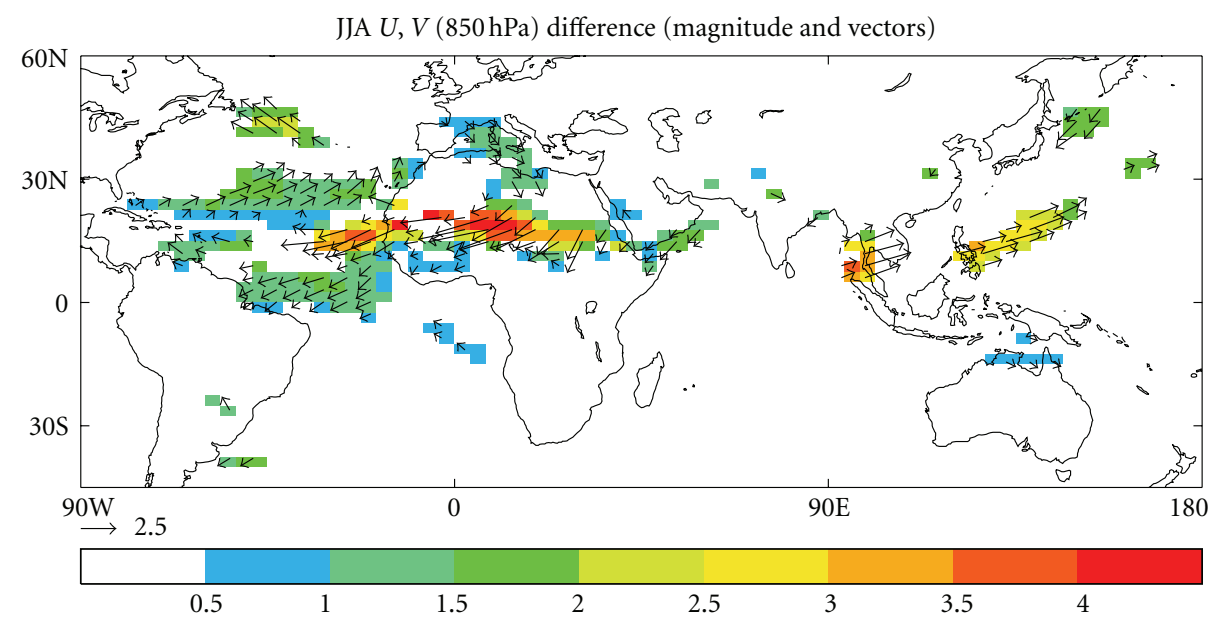

FIGURE 9: The changes in wind speed and direction at $850 \mathrm{hPa}$ for DEAD relative to CLIM during JJA.

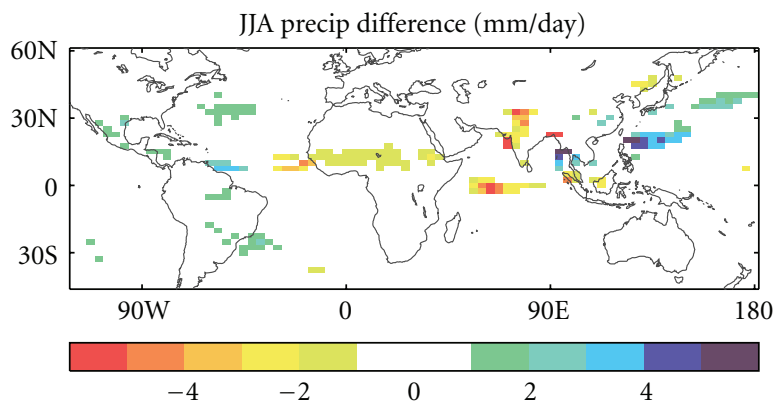

(a)

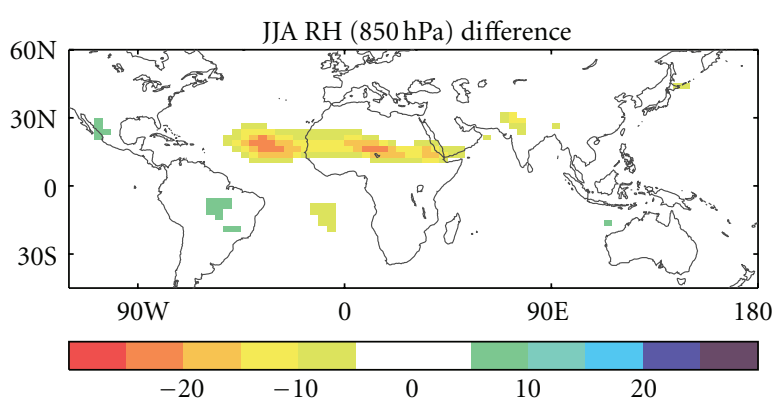

(b)

FIGURE 10: The difference in (a) precipitation ( $\mathrm{mm} /$ day) and (b) relative humidity (RH, \%) in JJA for DEAD relative to CLIM.

However, the AeroCom simulations only represented the year 2000, whereas the simulations undertaken in this study (using CLIM and DEAD) were run over sixteen years and may be more representative of the long-term climatological mean. Despite this difference, the majority of the annual mean AODs in both simulations, for any given individual year, lay within the AeroCom estimated range of global mean
AODs, which suggests that neither model lies outside the range of current dust modelling capabilities.

There were systematic differences between the two simulations however. The global annual mean AODs simulated using the CLIM scheme, were almost always consistently lower (fourteen of the sixteen simulated years) than those when using DEAD for any given year. Subsequently the 
climatological mean (1980-1995) dust AOD was lower in CLIM than for DEAD. The cause of these differences was due to the CLIM simulation containing a higher proportion of large particles, which could be deposited more rapidly from the atmosphere compared to those for DEAD, decreasing the dust load. Additionally DEAD contained more submicron particles than CLIM which enabled dust transport of particles with a high mass extinction efficiency [43] to greater distances in DEAD. Therefore the dust uplifted in the CLIM simulation had less time to interact effectively with radiation than in the DEAD simulation, resulting in lower AODs.

The dust size distribution in the CLIM scheme was also found to have too few small particles compared with the observational data compiled during the DODO field campaign. The size distribution of the dust uplifted using DEAD however was more comparable with the DODO observations, although there were still too few small particles. The close agreement between DEAD and DODO indicates that specifying the emitted dust size distribution based upon depositional data (as described in [28] and applied to the MetUM by [27]) may be more appropriate in GCM simulations. However, the size distribution of aeolian dust may vary regionally from the values calculated from the DODO campaign therefore specifying the modelled size distribution may not be appropriate for regional model simulations. A combination of the techniques used by CLIM and DEAD therefore may be appropriate for specifying the size distribution of aeolian dust.

Despite the differences in the modelled size distributions, the deposition rates in the CLIM and DEAD simulations compared well with the DIRTMAP observations. The CLIM scheme did less well than DEAD close to the major dust sources (such as the Sahara and Asia), which was due to the large proportion of coarse particles that could be deposited faster. Both CLIM and DEAD compared well with DIRTMAP in Antarctica except DEAD (CLIM) had slightly higher (lower) deposition rates than DIRTMAP, which was unsurprising given the higher proportion of fine (coarse) particles in DEAD (CLIM). The modelled deposition over eastern Greenland also compared well with DIRTMAP in both simulations although CLIM and DEAD had too little dust deposition in western Greenland.

While the differences in the simulated dust properties are important for understanding the uncertainty associated with specific uplift schemes, those differences also affected the modelled climate in each simulation. The higher global mean AODs with the DEAD scheme led to a large-scale cooling in JJA, particularly in North Africa and the Middle East, relative to CLIM (where the AODs reduced more rapidly away from the source). Conversely, within the source regions, the CLIM scheme had lower surface air temperatures, associated with the high AODs close to the source, than DEAD. The radiative impact of the dust also led to differences in the lowlevel circulation and precipitation rates close-to and remote from the Saharan dust source. These circulation changes still occurred despite the prescribed sea surface temperatures used in these simulations. This implies that the choice of dust uplift scheme has the potential to affect the tropical and subtropical circulation patterns even in AMIP-type simulations. Additionally, the differences in dust deposition in the Atlantic and Southern Ocean have important implications for ocean biogeochemistry and the carbon cycle. Therefore reducing the uncertainty associated with global dust modelling is important for all Earth-system modelling studies as it not only affects the global distribution of aeolian dust but also impacts significantly on the modelled climate.

\section{Acknowledgments}

DODO was funded by NERC via the SOLAS directed program (Grant NE/C517276/1) with the work undertaken by M. M. Joshi was funded by National Centres for Atmospheric Science (NCAS) Climate. The modelling work was carried out with the assistance of NCAS Computational Modelling Support (CMS). The aircraft data would not have been available without the enthusiastic work of the FAAM staff, DirectFlight, and Avalon Engineering. The authors would also like to thank Stephanie Woodward and Margaret Woodage for extremely helpful suggestions when reviewing earlier versions of this paper. Finally the authors would like to thank Charlie Zender for making the DEAD scheme code available to aid in generating the new uplift module in the MetUM.

\section{References}

[1] S. A. Christopher, P. Gupta, J. Haywood, and G. Greed, "Aerosol optical thicknesses over North Africa: 1. Development of a product for model validation using ozone monitoring instrument, multiangle imaging spectroradiometer, and aerosol robotic network," Journal of Geophysical Research D, vol. 113, no. 23, Article ID D00C04, 2008.

[2] P. Jiménez-Guerrero, C. Pérez, O. Jorba, and J. M. Baldasano, "Contribution of Saharan dust in an integrated air quality system and its on-line assessment," Geophysical Research Letters, vol. 35, no. 3, Article ID L03814, 2008.

[3] N. M. Mahowald, D. R. Muhs, S. Levis et al., "Change in atmospheric mineral aerosols in response to climate: last glacial period, preindustrial, modern, and doubled carbon dioxide climates," Journal of Geophysical Research D, vol. 111, no. 10, Article ID D10202, 2006.

[4] M. Yoshioka, N. M. Mahowald, A. J. Conley et al., "Impact of desert dust radiative forcing on sahel precipitation: relative importance of dust compared to sea surface temperature variations, vegetation changes, and greenhouse gas warming," Journal of Climate, vol. 20, no. 8, pp. 1445-1467, 2007.

[5] J. K. Moore, S. C. Doney, D. M. Glover, and I. Y. Fung, "Iron cycling and nutrient-limitation patterns in surface waters of the world ocean," Deep-Sea Research II, vol. 49, no. 1-3, pp. 463-507, 2002.

[6] I. Koren, Y. J. Kaufman, R. Washington et al., "The Bodélé depression: a single spot in the Sahara that provides most of the mineral dust to the Amazon forest," Environmental Research Letters, vol. 1, no. 1, Article ID 014005, 2006.

[7] C. Bouet, G. Cautenet, R. Washington et al., "Mesoscale modeling of aeolian dust emission during the BoDEx 2005 experiment," Geophysical Research Letters, vol. 34, no. 7, Article ID L07812, 2007.

[8] B. Heinold, J. Helmert, O. Hellmuth et al., "Regional modeling of Saharan dust events using LM-MUSCAT: model description 
and case studies," Journal of Geophysical Research D, vol. 112, no. 11, Article ID D11204, 2007.

[9] G. Kallos, A. Papadopoulos, P. Katsafados, and S. Nickovic, "Transatlantic Saharan dust transport: model simulation and results," Journal of Geophysical Research D, vol. 111, no. 9, Article ID D09204, 2006.

[10] W. L. Gates, J. S. Boyle, C. Covey et al., "An overview of the results of the Atmospheric Model Intercomparison Project (AMIP I)," Bulletin of the American Meteorological Society, vol. 80, no. 1, pp. 29-55, 1999.

[11] M. C. Todd, D. Bou Karam, C. Cavazos et al., "Quantifying uncertainty in estimates of mineral dust flux: an intercomparison of model performance over the Bodélé depression, northern Chad," Journal of Geophysical Research D, vol. 113, no. 24, Article ID D24107, 2008.

[12] I. Uno, Z. Wang, M. Chiba et al., "Dust Model Intercomparison (DMIP) study over Asia: overview," Journal of Geophysical Research D, vol. 111, no. 12, Article ID D12213, 2006.

[13] S. Kinne, M. Schulz, C. Textor et al., "An AeroCom initial assessment-optical properties in aerosol component modules of global models," Atmospheric Chemistry and Physics, vol. 6, no. 7, pp. 1815-1834, 2006.

[14] P. R. Colarco, O. B. Toon, and B. N. Holben, "Saharan dust transport to the Caribbean during PRIDE: 1. Influence of dust sources and removal mechanisms on the timing and magnitude of downwind aerosol optical depth events from simulations of in situ and remote sensing observations," Journal of Geophysical Research D, vol. 108, article 8589, 20 pages, 2003.

[15] E. Nowottnick, P. Colarco, R. Ferrare et al., "Online simulations of mineral dust aerosol distributions: comparisons to namma observations and sensitivity to dust emission parameterization," Journal of Geophysical Research D, vol. 115, no. 3, Article ID D03202, 2010.

[16] C. Luo, N. Mahowald, and C. Jones, "Temporal variability of dust mobilization and concentration in source regions," Journal of Geophysical Research D, vol. 109, no. 20, Article ID D20202, 13 pages, 2004.

[17] T. C. Johns, C. F. Durman, H. T. Banks et al., "The new Hadley Centre Climate Model (HadGEM1): evaluation of coupled simulations," Journal of Climate, vol. 19, no. 7, pp. 1327-1353, 2006.

[18] G. M. Martin, M. A. Ringer, V. D. Pope, A. Jones, C. Dearden, and T. J. Hinton, "The physical properties of the atmosphere in the new Hadley Centre Global Environmental Model (HadGEM1). Part 1: model description and global climatology," Journal of Climate, vol. 19, no. 7, pp. 1274-1301, 2006.

[19] W. J. Collins, N. Belloiun, M. Doutriaux-Boucher et al., "Evaluation of HadGEM2 model," Hadley Centre Technical Note 74, 2008, http://www.metoffice.gov.uk/media/pdf/ 8/7/HCTN_74.pdf.

[20] The HadGEM2 Development Team, "The HadGEM2 family of Met Office Unified Model climate configurations," Geoscientific Model Development, vol. 4, pp. 723-757, 2011.

[21] S. Woodward, "Modeling the atmospheric life cycle and radiative impact of mineral dust in the Hadley centre climate model," Journal of Geophysical Research D, vol. 106, no. 16, pp. 18155-18166, 2001.

[22] L. C. Shaffrey and Coauthors, "U.K. HiGEM: the new U.K. high-resolution global environment model-model description and basic evaluation," Journal of Climate, vol. 22, pp. 1861-1896, 2011.
[23] M. J. Woodage, A. Slingo, S. Woodward, and R. E. Comer, "U.K. HiGEM: simulations of desert dust and biomass burning aerosols with a high-resolution atmospheric GCM," Journal of Climate, vol. 23, no. 7, pp. 1636-1659, 2010.

[24] R. A. Bagnold, The Physics of Blown Sand and Desert Dunes, Methuen, London, UK, 1941.

[25] S. Woodward, "Mineral dust in HadGEM2," Hadley Centre Technical Note 87, 2011, http://www.metoffice.gov.uk/ media/pdf/l/p/HCTN_87.pdf.

[26] Global Soil Data Task Group, Global Gridded Surfaces of Selected Soil Characteristics (IGBP-DIS), Oak Ridge National Laboratory Distributed Active Archive Center, Oak Ridge, Tenn, USA, 2000.

[27] D. Ackerley, E. J. Highwood, M. A. J. Harrison et al., "The development of a new dust uplift scheme in the Met Office Unified Model," Meteorological Applications, vol. 16, no. 4, pp. 445-460, 2009.

[28] C. S. Zender, H. Bian, and D. Newman, "Mineral Dust Entrainment and Deposition (DEAD) model: description and 1990s dust climatology," Journal of Geophysical Research D, vol. 108, no. 14, pp. 1-19, 2003.

[29] F. Fécan, B. Marticorena, and G. Bergametti, "Parametrization of the increase of the aeolian erosion threshold wind friction velocity due to soil moisture for arid and semi-arid areas," Annales Geophysicae, vol. 17, no. 1, pp. 149-157, 1999.

[30] B. N. Holben, T. F. Eck, I. Slutsker et al., "A federated instrument network and data archive for aerosol characterization," Remote Sensing of Environment, vol. 66, no. 1, pp. 1-16, 1998.

[31] Y. J. Kaufman, I. Koren, L. A. Remer, D. Tanré, P. Ginoux, and S. Fan, "Dust transport and deposition observed from the Terra-Moderate Resolution Imaging Spectroradiometer (MODIS) spacecraft over the Atlantic ocean," Journal of Geophysical Research D, vol. 110, no. 10, pp. 1-16, 2005.

[32] N. Bellouin, O. Boucher, J. Haywood et al., "Improved representation of aerosols for HadGEM2," Hadley Centre Technical Note 73, 2007, http://www.metoffice.gov.uk/media/ pdf/8/f/HCTN_73.pdf.

[33] C. Textor, M. Schulz, S. Guibert et al., "Analysis and quantification of the diversities of aerosol life cycles within AeroCom," Atmospheric Chemistry and Physics, vol. 6, no. 7, pp. 1777$1813,2006$.

[34] N. Huneeus, M. Schulz, Y. Balkanski et al., "Global dust model intercomparison in AeroCom phase i," Atmospheric Chemistry and Physics, vol. 11, no. 15, pp. 7781-7816, 2011.

[35] C. L. McConnell, E. J. Highwood, H. Coe et al., "Seasonal variations of the physical and optical characteristics of Saharan dust: results from the Dust Outflow and Deposition to the Ocean (DODO) experiment," Journal of Geophysical Research, vol. 113, Article ID D14S05, 19 pages, 2008.

[36] B. T. Johnson and S. R. Osborne, "Physical and optical properties of mineral dust aerosol measured by aircraft during the GERBILS campaign," Quarterly Journal of the Royal Meteorological Society, vol. 137, no. 658, pp. 1117-1130, 2011.

[37] B. Weinzierl, A. Petzold, M. Esselborn et al., "Airborne measurements of dust layer properties, particle size distribution and mixing state of Saharan dust during SAMUM 2006," Tellus B, vol. 61, no. 1, pp. 96-117, 2009.

[38] A. J. Ridgwell, "Dust in the Earth system: the biogeochemical linking of land, air and sea," Philosophical Transactions of the Royal Society A, vol. 360, no. 1801, pp. 2905-2924, 2002.

[39] T. D. Jickells, Z. S. An, K. K. Andersen et al., "Global iron connections between desert dust, ocean biogeochemistry, and climate," Science, vol. 308, no. 5718, pp. 67-71, 2005. 
[40] I. Tegen, S. P. Harrison, K. Kohfeld, I. C. Prentice, M. Coe, and M. Heimann, "Impact of vegetation and preferential source areas on global dust aerosol: results from a model study," Journal of Geophysical Research D, vol. 107, no. 21, article 4576, 2002.

[41] K. E. Kohfeld and S. P. Harrison, "DIRTMAP: the geological record of dust," Earth-Science Reviews, vol. 54, no. 1-3, pp. 81114, 2001.

[42] K. E. Kohfeld, "DIRTMAP version 2. LGM and late holocene eolian fluxes from ice cores, marine sediment traps, marine sediments, and loess deposits," IGBP PAGES/World Data Center for Paleoclimatology Data Contribution Series \#2002045, NOAA/NGDC Paleoclimatology Program, Boulder, Colo, USA, 2002.

[43] J. H. Seinfeld and S. Pandis, Atmospheric Chemistry and Physics, John Wiley and Sons, New York, NY, USA, 1998. 

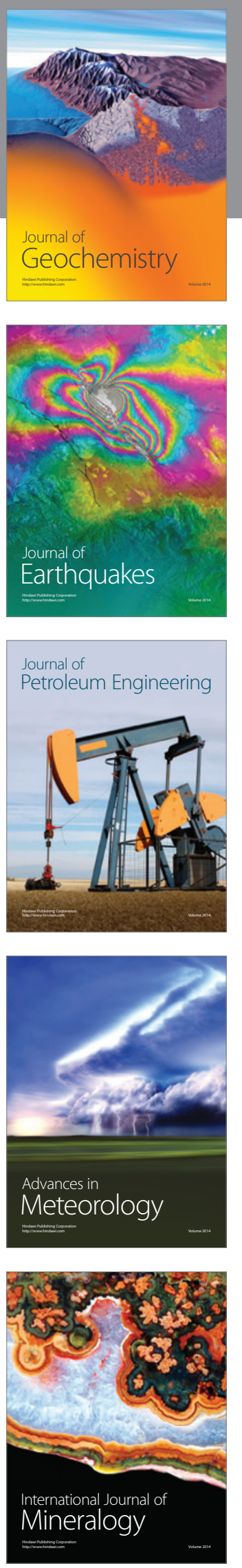
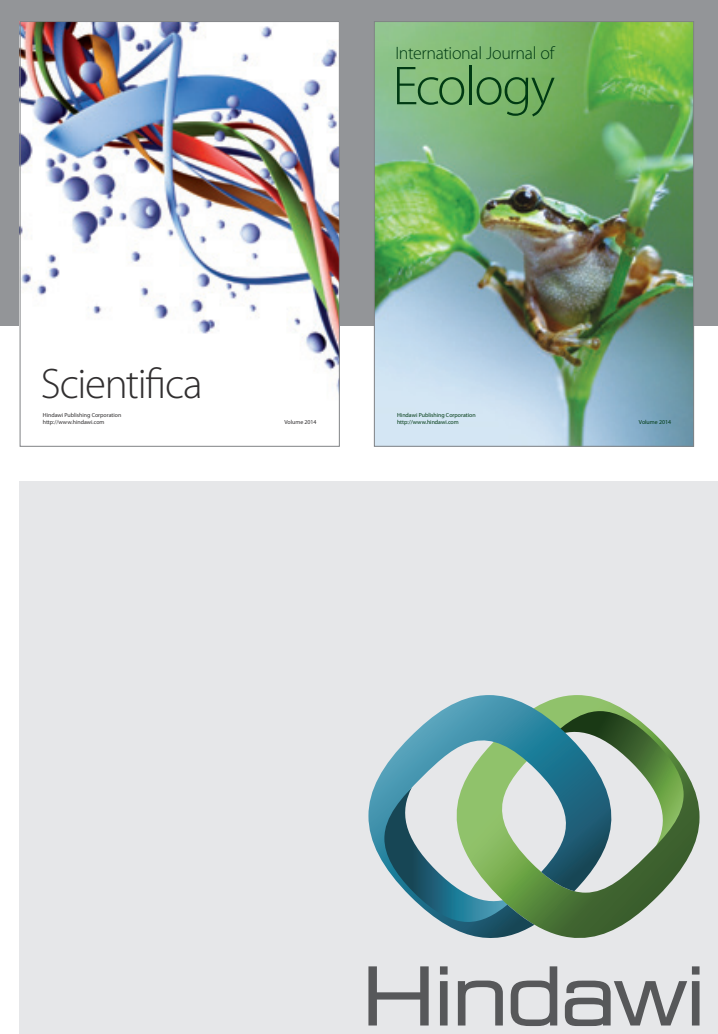

Submit your manuscripts at http://www.hindawi.com
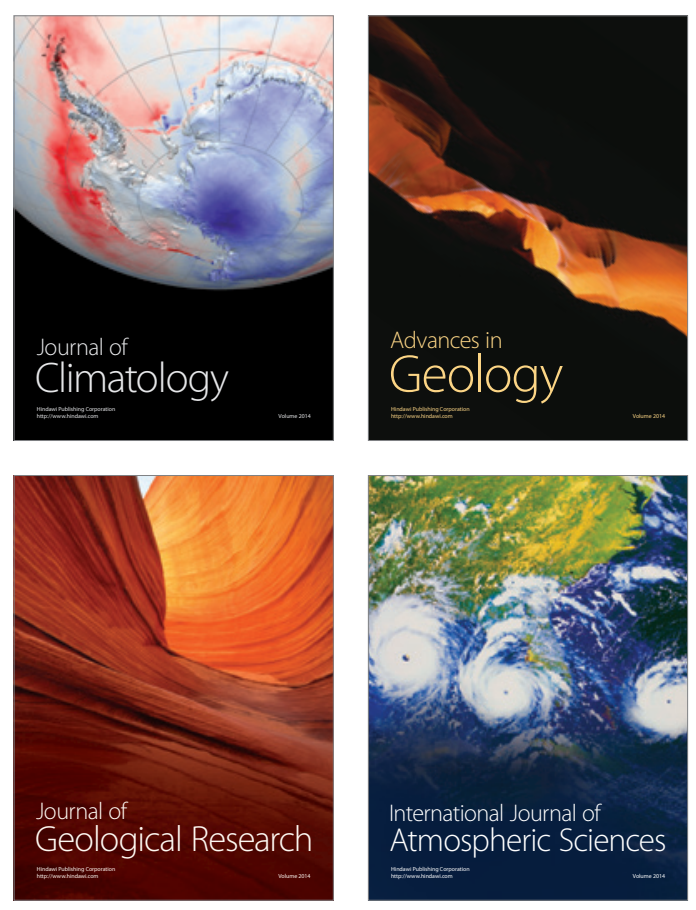
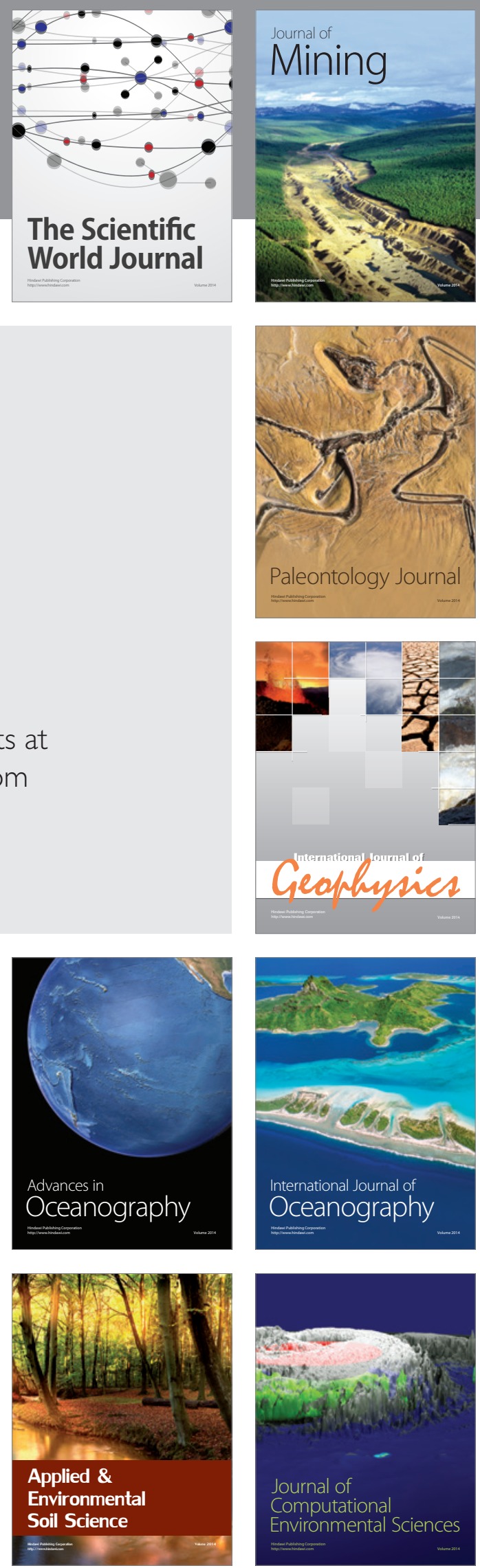